Article

\title{
Large-Scale Assessment of Coastal Aquaculture Ponds with Sentinel-1 Time Series Data
}

\author{
Marco Ottinger ${ }^{1, *}$, Kersten Clauss ${ }^{1}$ and Claudia Kuenzer ${ }^{2}$ \\ 1 Department of Remote Sensing, Institute of Geography and Geology, University of Wuerzburg, \\ D-97074 Wuerzburg, Germany; kersten.clauss@dlr.de \\ 2 German Aerospace Center (DLR), German Remote Sensing Data Center (DFD), D-82234 Wessling, Germany; \\ claudia.kuenzer@dlr.de \\ * Correspondence: marco.ottinger@dlr.de; Tel.: +49-8153-28-1510
}

Academic Editors: Deepak R. Mishra, Xiaofeng Li and Prasad S. Thenkabail Received: 10 February 2017; Accepted: 27 April 2017; Published: 4 May 2017

\begin{abstract}
We present an earth observation based approach to detect aquaculture ponds in coastal areas with dense time series of high spatial resolution Sentinel-1 SAR data. Aquaculture is one of the fastest-growing animal food production sectors worldwide, contributes more than half of the total volume of aquatic foods in human consumption, and offers a great potential for global food security. The key advantages of SAR instruments for aquaculture mapping are their all-weather, day and night imaging capabilities which apply particularly to cloud-prone coastal regions. The different backscatter responses of the pond components (dikes and enclosed water surface) and aquaculture's distinct rectangular structure allow for separation of aquaculture areas from other natural water bodies. We analyzed the large volume of free and open Sentinel-1 data to derive and map aquaculture pond objects for four study sites covering major river deltas in China and Vietnam. SAR image data were processed to obtain temporally smoothed time series. Terrain information derived from DEM data and accurate coastline data were utilized to identify and mask potential aquaculture areas. An open source segmentation algorithm supported the extraction of aquaculture ponds based on backscatter intensity, size and shape features. We were able to efficiently map aquaculture ponds in coastal areas with an overall accuracy of 0.83 for the four study sites. The approach presented is easily transferable in time and space, and thus holds the potential for continental and global mapping.
\end{abstract}

Keywords: aquaculture; SAR; Sentinel-1; time series; image segmentation; remote sensing; ponds; coastal zone; river delta

\section{Introduction}

Aquaculture is one of the fastest growing food production sectors worldwide, an important food supply in many countries, main protein source for hundreds of million people and in the spotlight for its potential to support future food security at global scale [1]. According to the Food and Agriculture Organization of the United Nations (FAO) human consumption of farmed species exceeded that of capture fisheries for the first time in 2014 [2]. Global aquaculture production more than doubled from 32.4 million tons in 2000 to 73.8 million tons in 2014 [2] and received a record share of 43.1 percent of the total 168.4 million tons of aquatic organisms such as fish, shrimp and mollusks produced. Asia alone generates 90 percent of the total global aquaculture volume which is mainly produced by pond systems in fertile coastal environments. We developed a framework to process time series of earth observation satellite data to detect and map aquaculture in coastal area at a very large scale. Based on open-source tools, we developed an approach to process large and dense time series of high resolution Synthetic Aperture Radar (SAR) data acquired by the European Sentinel-1A C-band SAR satellite and utilized an image segmentation method supported by terrain information (coastline data and DEM data) to extract 
aquaculture ponds. We focus on four significant coastal hotspots in China and Vietnam that cover major river deltas and represent one of the world's most important aquaculture production areas.

Aquaculture ponds have been installed in coastal environments, often in valuable low lying coastal ecosystems with rich biodiversity and high ecological value such as river deltas, wetlands, coastal forests and mangroves. In East and Southeast Asia, more and more farmers shift from traditional rice farming to more profitable aquaculture or hybrid rice-shrimp or rice-fish systems [3] to generate more income. The rapid growth of aquaculture (see Figure 1) coincides with an increased input of feeds (fish oil and fish meal), and use of antibiotics, pesticides and other chemicals [1,4]. Although aquaculture has many positive impacts on local livelihoods, poverty reduction, nutrition, and regional economy, it is also responsible for increased environmental degradation and biodiversity loss. Intensive aquaculture and the discharge of untreated waste waters are major causes for environmental pollution as demonstrated by the examples of catfish production in Vietnam or shrimp production in China [5].

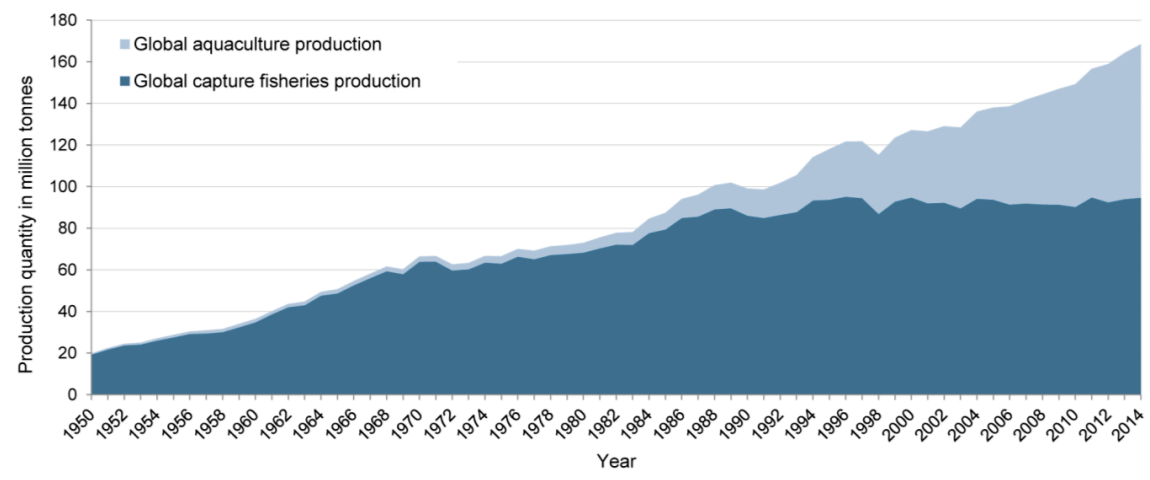

Figure 1. Annual global production volume of aquaculture and capture fisheries from 1950 to 2014. Data source: FAO.

In regard of future food security, a global assessment of aquaculture and information relevant for assessing stocking density is of global concern. Quantities on aquaculture production are generally collected at national level and submitted to the FAO, who provide a variety of fishery statistical datasets on national, regional and global level. However, there are not yet any harmonized standards for data collection and independent alternative information sources are limited. The Fisheries and Aquaculture Department of the FAO recently stated that remote sensing is a promising assessment tool to help estimate fisheries productivity and yield [2]. On the other hand, it is also stated that their application to inland fisheries and aquaculture is lagging far behind that in other sectors [2]. Earth observation by satellite remote sensing holds a large potential to complement the need for routine and reliable data on aquaculture at large scales. The free and open data access to long-term missions such the US sensors ASTER, MODIS and Landsat fleet, the European ERS-1/2, Envisat, or to ESA's recently launched Sentinels [6] fosters the use of earth observation data and products for applications in the aquaculture sector. Satellite derived data products can significantly contribute to large-scale mapping of aquaculture for a better understanding and management and help to improve the quantification of fish and shrimp ponds and related production volumes to ensure the availability of comparable statistics among countries and regions.

Fish and shrimp ponds generally have a distinct rectangular shape and are almost constantly filled with water, partially or fully drained during harvest. Aquaculture ponds are typically shallow water surfaces enclosed by dykes or levees. The size of ponds ranges from very small household systems to very large community managed systems several hectares in size [7]. Aquaculture ponds can be detected with radar imagery based on a high contrast ratio between the smooth water surface (low radar backscatter) and the rougher land surface, which scatters more energy in all directions including back to the sensor [8]. Ponds appear in radar images as dark areas (low backscatter) distinguishable primarily by shape from other open water bodies [9]. Active SAR sensors transmit microwaves of a 
certain wavelength towards a target and measure the backscattered signal. The information contained in a radar image is a result of signal interaction (see Figure $2 \mathrm{a}-\mathrm{c}$ ) with the surface and represents the amount of backscatter from the illuminated target on the ground. Radar backscatter is related to surface roughness and the dielectric properties of a surface but also depends on incidence angle and wavelength. It is suitable to detect water surfaces as they usually act as specular reflectors (see Figure 2a). Wind and paddlewheel aeration systems increase water surface roughness and result in diffuse surface scattering (see Figure 2c).

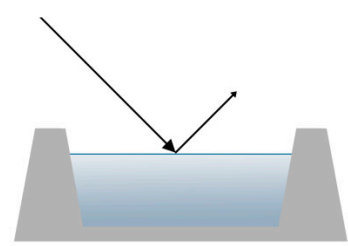

(a)

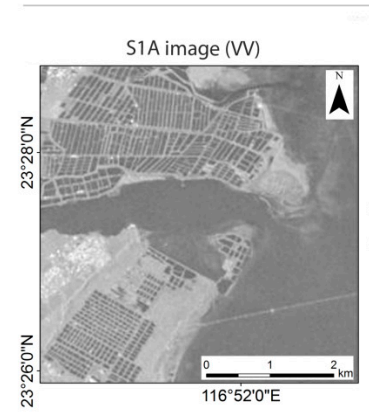

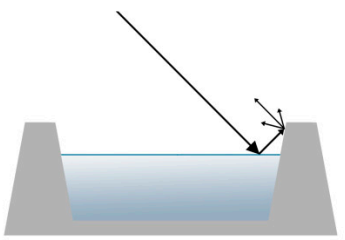

(b)

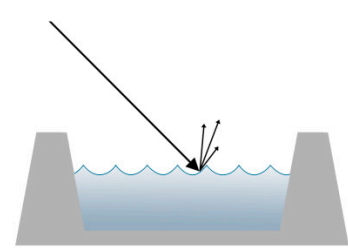

(c)
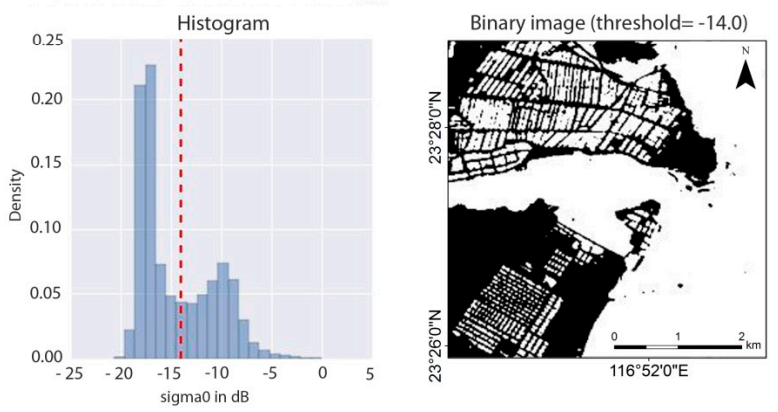

Figure 2. (Top) Examples of radar interaction with aquaculture ponds: (a) specular reflection (smooth water surface); (b) corner/embankment; and (c) diffuse reflection (rough water surface). (Bottom) S1A image (left); related histogram (center); and binary image water-non water (right).

A high spatial resolution is needed to detect the enclosing pond features such as embankments, levees or dikes which may have a width of only a few meters. Therefore, spatial resolution is very important to distinguish not only between ponds and land surfaces but also to separate adjacent ponds from each other. Since aquaculture ponds may often be found in checkerboard pattern (particular for large intensified aquaculture farms) and placed closely together, spatial resolution is an important and clearly limiting factor for aquaculture pond detection. Therefore shape features provide important supplementary information for a better differentiation of natural water surfaces and pond structures [9].

High resolution satellite imagery has great potential for mapping aquaculture ponds. Optical sensors have been used to detect aquaculture areas by [10-17]. An advanced object-based approach for SPOT-5 and WorldView-1 data to detect aquaculture ponds in a coastal site in Vietnam was carried out by Virdis [18]. In general, detailed mapping of aquaculture on single pond level has scarcely been investigated, in particular on large spatial scales. The high cost of optical satellite data at very fine spatial resolution is a major constraint for the upscaling of aquaculture detection at large spatial and temporal scales. Cloud cover is a clear drawback in optical remote sensing since it limits data availability, particularly in humid tropical regions [19]. Compared to optical sensors, satellite synthetic aperture radar (SAR) systems have the capability of all-weather and day-night acquisition and are therefore very suitable for mapping aquaculture in coastal areas.

Data continuity is required in order to ensure a better temporal resolution for the identification of water and other land cover and being capable to differentiate between standing water bodies and flooded areas. Therefore, a dense time series of satellite data is needed to distinguish between rectangular, permanently water-filled aquaculture ponds and other rectangular surface features which can be covered with water at the sensing date but are flooded periodically. Potential of temporally 
dense optical data for large-scale mapping of water have been demonstrated for MODIS [20] data at $250 \mathrm{~m}$ and Landsat [21] data at $30 \mathrm{~m}$. Although the recently launched Sentinel-2 satellites now provide high resolution optical imagery suitable for the detection of very small aquaculture ponds, cloud cover in coastal areas severely limits the use of optical sensors. The Sentinel-1 SAR sensors however offer short revisit time, appropriate ground resolution, wide area coverage, and all-weather capabilities that allow large-scale and continuous mapping and monitoring.

Many studies have drawn attention to the extraction of surface water from space-borne radar sensors [22-25], in particular for applications in the field of flood detection and monitoring which has been widely investigated [8,26-32]. Most recently, Amitrano et al. [33] evaluated Sentinel-1 data for monitoring reservoirs and Herman and Carlos [34] analyzed Sentinel-1 images for ship detection in the context of maritime surveillance. There are some studies that used SAR data to map aquaculture ponds [35-40] but these approaches are local and do not utilize dense time series of SAR data to detect and map aquaculture ponds. We present the first known object based attempt to map aquaculture ponds on large scale with time series of Sentinel-1 data.

\section{Study Area}

The cultivation of fish, shrimp and other crustaceans increased rapidly (see Figure 1) and more than 90 percent of the total global aquaculture output is being produced in Asia [41]. The coastal zone of China and Vietnam with its diversity of lagoons, estuaries, river deltas and rich water resources offer ideal environments to cultivate fish and crustaceans. With an annual output of more than 66 million tons [42], China is by far the world's largest aquaculture producer. Together with Vietnam, which ranks fourth in the world, these two Asian countries contribute more than two-thirds of the world's total production in 2014. For this reason, research and development of aquaculture in the coastal zones of China and Vietnam, with over 18,000 km shoreline length (China: 14,500 km; Vietnam: $3444 \mathrm{~km}$ ), will be in spotlight for its international economic stature (aquatic food exports and trade), employment prospects and potentials for global food security.

We focus on four major river deltas distributed along the coasts of China and Vietnam (see Figure 3) representing one of the largest and most significant aquaculture production centers both at the national and international level: The Mekong Delta at the southern end of Vietnam; the Red River Delta in the north of Vietnam; the Pearl River Delta in Guangdong Province, south China; and the Yellow River Delta in Shandong Province, north China. The common characteristic of these four deltas is their flat topography, existing infrastructure, and rich natural resources [43]. Table 1 presents facts about the four study areas. All authors of this paper have in-depth and long-term in-situ knowledge of the river deltas addressed.

The Mekong Delta (MRD) in Vietnam is comprised of 13 provinces, inhabited by 18 million people [30] and covers a total area of approximately $39,000 \mathrm{~km}^{2}$ of which $24,000 \mathrm{~km}^{2}$ are used for rice farming and aquaculture [44]. Fish and shrimp farming have a long tradition and increased rapidly while becoming a very important industry (international trade and export) and the dominant land use in many coastal areas [45]. More farmers also shift from traditional rice farming to saline aquaculture to increase income or to adapt to increased salinity levels since sea water intrusion is a critical issue in the delta [3]. More than 70 percent of the total national fish and almost 80 percent of the total shrimp are produced in the delta [46].

Table 1. Overview of the four river delta areas in this study.

\begin{tabular}{ccccc}
\hline Study Area & Country & Total Area $\left.\mathbf{( k m}^{2}\right)$ & Population & Coastline \\
& $\mathbf{1}(\mathbf{k m})$ \\
\hline Mekong Delta & Vietnam & 39,300 & $18,000,000$ & 999 \\
Red River Delta & Vietnam & 15,500 & $20,200,000$ & 287 \\
Pearl River Delta & China & 42,300 & $57,000,000$ & 1857 \\
Yellow River Delta & China & 7500 & $5,900,000$ & 389 \\
\hline
\end{tabular}

${ }^{1}$ Data based on generalized coastlines derived from GADM dataset [40]. 

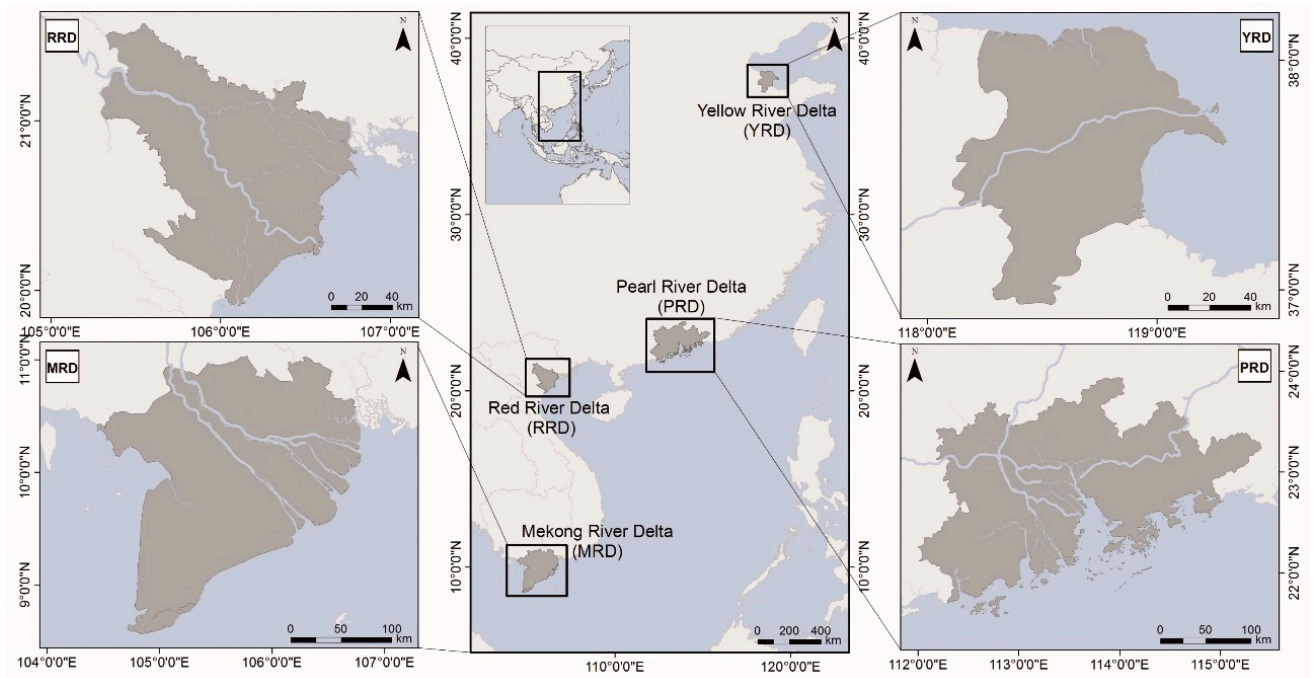

Figure 3. Location and overview of the four study areas: The Mekong Delta (MRD) and Red River Delta (RRD) in Vietnam and the Pearl River Delta (PRD) and Yellow River Delta (YRD) in China.

The Red River Delta (RRD) is Vietnam's second largest delta and includes eight provinces, the capital city of Hanoi and the main port of Hai Phong. The region experienced rapid urbanization and industrialization and became the most important economic zone in Vietnam [47,48]. Rising sea level, increasing salt water intrusion, and decrease in rainfall upstream are major factors for salinization in the coastal area of the delta. In some areas, cultivation is limited due to high salinity levels and farmers switch from rice farming to saline shrimp farming [48].

The Pearl River Delta (PRD) is located in Guangdong Province of China, and includes major metropolitan areas such as Hong Kong, Macao, Guangzhou, and Shenzhen. Due to the rapid economic development during the past 30 years, the greater delta region became one of China's most important economic zones [49-51] and aquaculture has been spreading rapidly in the last years. The World Bank recently reported that the Pearl River Delta urban area grew from 27 million in 2000 to 42 million people in 2010 and has overtaken Tokyo to become the largest urban area in the world in both size and population [52].

The Yellow River Delta (YRD) is the delta of China's second largest river and located at the west coast of the Bohai Sea. The delta has one of the world's highest sedimentation and erosion rates and includes the most integrated, widest, and youngest estuary wetland ecosystem in China $[53,54]$. Oil and gas exploitation favored the rapid industrial development, urban growth, and population increase in this region. Aquaculture has been rapidly increased in the delta followed by a coastward expansion which caused considerable loss of tidal wetlands.

\section{Data}

\subsection{Sentinel-1 Data}

For each study site, we used all available Sentinel-1A dual-polarized $(\mathrm{VV}+\mathrm{VH})$ data in Interferometric Wide-Swath Mode (IW) and Ground Range Detected High Resolution (GRDH) format for the time period from September 2014 to September 2016 [55]. IW is the default mode over land which captures three sub-swaths using Terrain Observation with Progressive Scans SAR (TOPSAR) recording data with a $250 \mathrm{~km}$ swath at $5 \mathrm{~m}$ by $20 \mathrm{~m}$ spatial resolution (resampled to $10 \mathrm{~m}$ spacing for GRDH products).

Sentinel-1 is a constellation of two satellites with synthetic aperture radar instrument operating at C-band with a frequency of $5.4 \mathrm{GHz}$. Sentinel-1A and Sentinel-1B were launched in April 2014 and April 2016, respectively, sharing the same orbital plane for continuous radar mapping of the Earth with enhanced revisit frequency, coverage and timeliness. We only used Sentinel-1A data because 
Sentinel-1B has just completed its commissioning phase in mid-September 2016. The Sentinel-1 mission provides day-and-night and all-weather observation capabilities [56,57] and ensures data continuity along with the upcoming launches of two additional satellites (Sentinel-1C and 1D). With a revisit time of 12 days (six days for two satellites) and high spatial resolution, Sentinel-1 allows frequent and effective mapping and monitoring of aquaculture at global level.

The Sentinel-1 images are overlapping depending on the combination of orbit (descending or ascending). Figure 4 shows the swath pattern and the data coverage of Sentinel-1A IW GRDH scenes for the study sites. The coverage of Sentinel-1A data not only varies among different regions but also within the study areas. More than 100 scenes are available for the two-year investigation period. With Sentinel-1A and Sentinel-1B, temporal resolution and data coverage will increase and improve mapping of aquaculture in coastal areas.
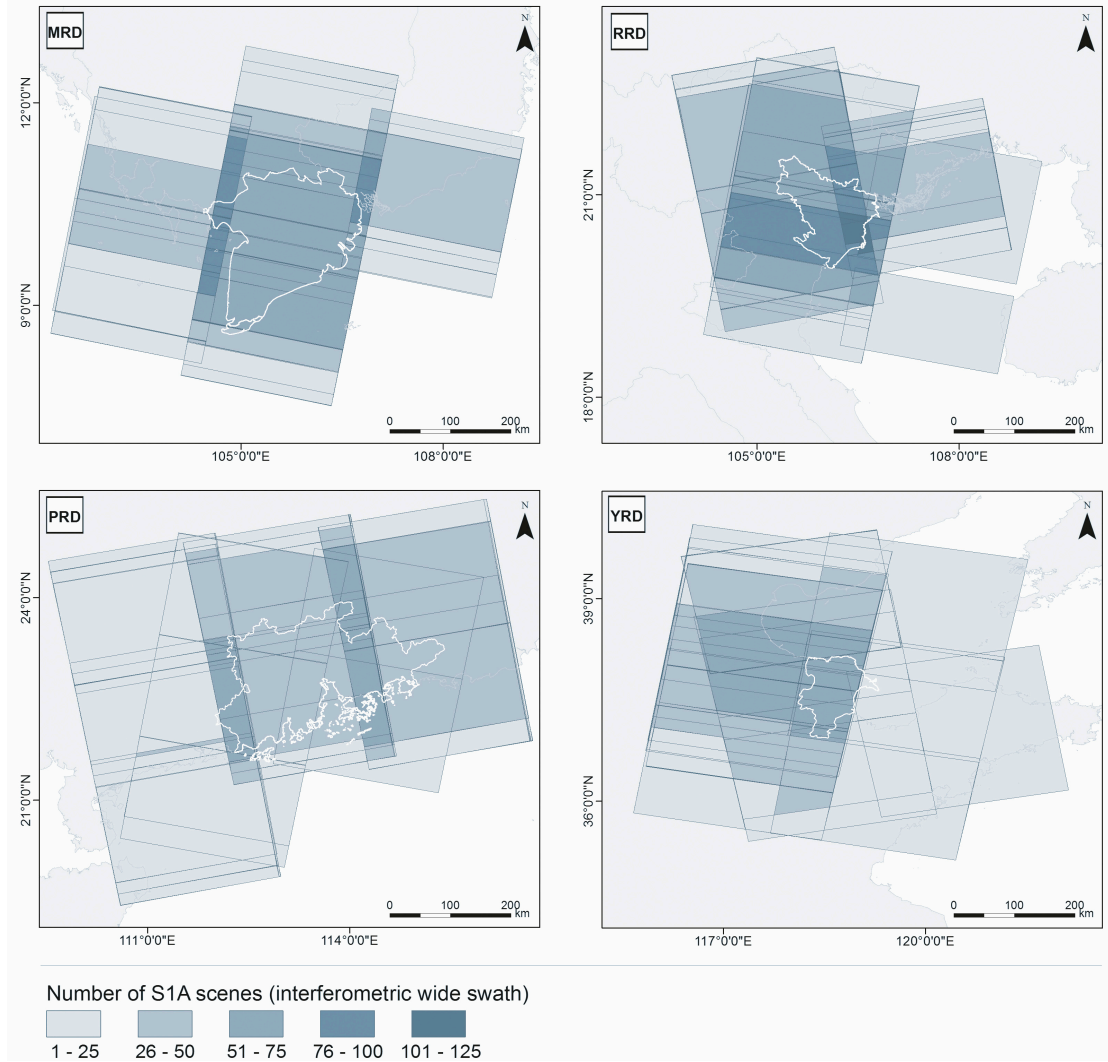

Figure 4. Coverage frequency of dual-polarized Sentinel-1A scenes in the study period from 30 September 2014 to 30 September 2016 for each study area.

\subsection{Aquaculture Pond Samples and Shape Metrics}

More than 3000 aquaculture pond data were systematically collected and mapped in the coastal zone (20 km buffer) of Vietnam and China based on in situ mapping, and high resolution satellite imagery acquired after September 2014. We calculated size and shape metrics for each pond. The satellite image based aquaculture samples were identified visually through on-screen digitizing from Google Earth imagery. Although the resolution of Google Earth imagery varies spatially and temporally and cannot be used everywhere, we considered it as a data source for the sampling since the coverage of up-to-date and high resolution images was very satisfying for most parts of the study areas.

Earth observation derived aquaculture ponds were selected under two conditions: (1) the acquisition date of the high resolution satellite imagery may not be older than September 2014; and (2) only ponds located in the coastal zone defined as the area within a distance of 20 kilometer from the shoreline were selected for the sampling. To quantitatively describe the geometry of the 
sampled aquaculture ponds for each study area, we calculated area and perimeter for all polygons. Furthermore, two compactness metrics were computed to quantify the complexity of pond shape for the samples in each study area and to provide useful information for the detection of differences among the river deltas (see Figure 5). The analysis and description of the shapes of objects are important topics in pattern recognition [58].

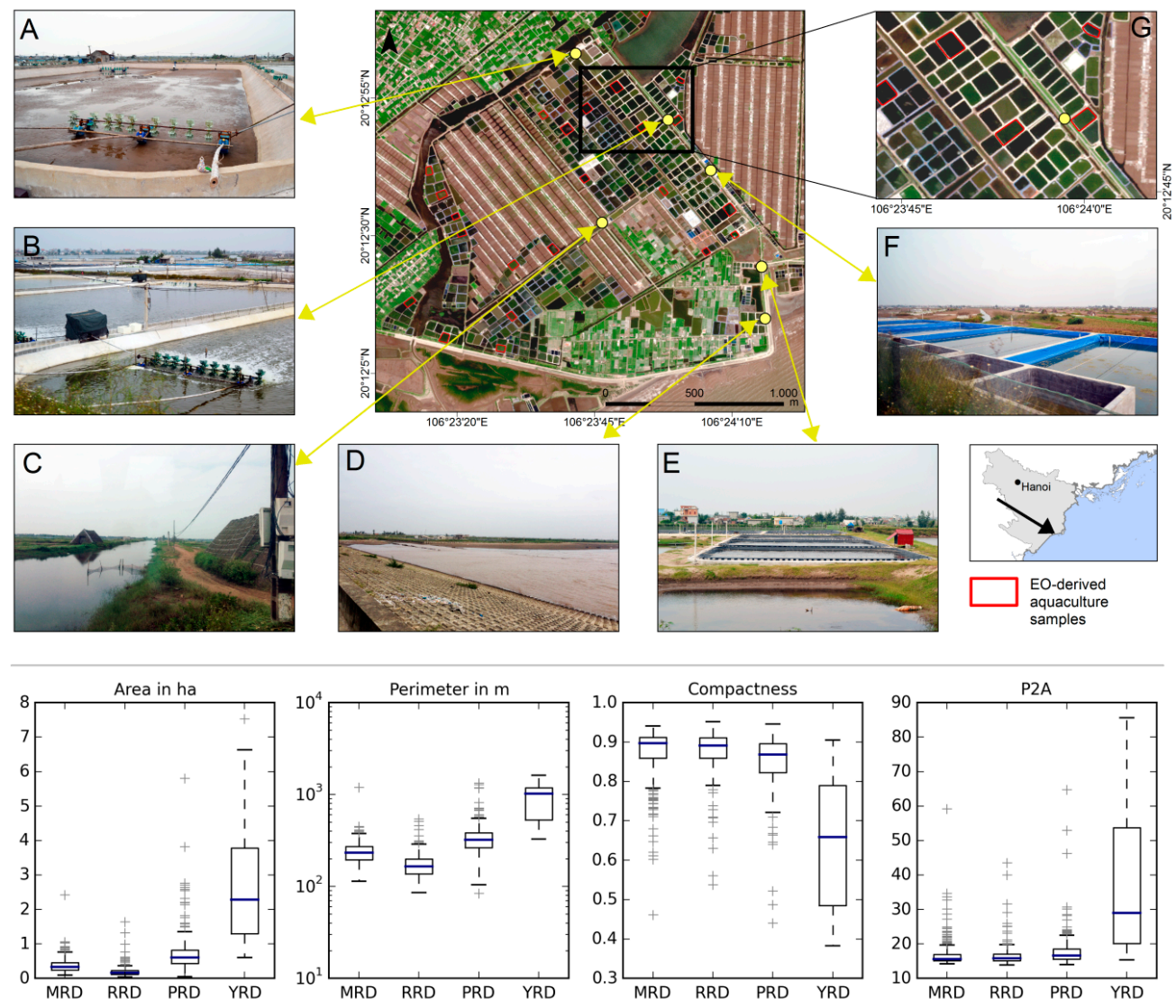

Figure 5. (Top) Field photographs taken within the DeltAdapt project in October 2014 in the Giao Thuy district, Nam Dinh province, Red River Delta, Vietnam: (A) drained shrimp pond; (B) shrimp ponds with active paddle aerators; (C) water channel; (D) dike; (E) mussel pond; (F) shrimp ponds; and $(\mathrm{G})$ WorldView-02 image with aquaculture samples (red) derived from earth observation data. (Bottom) Comparative boxplots of the calculated area, perimeter, compactness and P2A for the aquaculture samples in the corresponding study areas.

$$
\begin{gathered}
\mathrm{P} 2 \mathrm{~A}=\frac{\text { perimeter }^{2}}{\text { area }} \\
\text { Compactness } \mathrm{C}=\sqrt{\frac{\mathrm{Area}}{\mathrm{Bi}}}, \text { where } \mathrm{Bi}=\frac{\text { perimeter }^{2}}{4 \pi}
\end{gathered}
$$

Shape compactness is often calculated with the simple ratio of the squared shape perimeter to shape area (P2A) [58]. The shape index or compactness ratio $C$ is defined by the square root of the ratio of area divided by the area of a circle with the perimeter [59]. This index is dimensionless, meaning that it is not affected by the size of the object and has value of 1 for a circle and a range of 0 to 1 for all plane shapes. The interpretation varies among the different shape metrics but in general higher values mean greater shape complexity [59]. 


\subsection{DEM Data}

The digital elevation model (DEM) acquired during the Shuttle Radar Topography Mission (SRTM) was used to derive terrain information (height and slope) and determine potential aquaculture areas within the study sites. We acquired the SRTM Version 3.0 Global 1 arc second dataset (SRTMGL1) which was released in 2015 and is publicly available in worldwide coverage (between $60^{\circ}$ north and $56^{\circ}$ south latitude). This dataset offers void filled data at a high spatial resolution of 30 meters and is distributed free of charge by United States Geological Survey (USGS). We acquired 292 tiles from the USGS server for the entire coastal area of Vietnam and China.

We calculated slope from the SRTM DEM file using the Geospatial Data Abstraction Library (GDAL) tools (Appendix A). With increasing slope, it becomes less likely that surface water will be present at a location. Therefore a high value of slope would imply that classified aquaculture is less likely to be correct. Slope was calculated in decimal degree values ranging from 0 to 90 .

\subsection{Coastline Data}

A detailed coastline dataset that covers the entire coastal area of East and Southeast Asia was kindly provided by the Institute of Geographic Sciences and Natural Resources Research (IGSNRR), Chinese Academy of Sciences, and has been used to generate a binary land and water mask $[60,61]$. This dataset proved to be more detailed and up-to-date than other globally available shoreline datasets, such as Global Administrative Areas (GADM), World Vector Shoreline (WVS), Vector Map Level 1 (VMAP1), and Natural Earth.

In addition, the freely accessible SRTM water body data, SWBD [62] has been downloaded and compiled for the study sites in order to obtain a static water mask to exclude standing water bodies (e.g., rivers or small channels). The tiles were merged to mosaics for each study area and we selected all waterbodies which are connected to the ocean. In this way we were able to exclude coastal inland water bodies from the SWBD data, ensuring that the static water mask does not contain any aquaculture areas. The final static water mask contains marine water bodies and greater rivers that discharge to the sea and are connected with the coastal waters.

\section{Methods}

\subsection{SAR Data Pre-Processing}

Sentinel-1A data in the IW acquisition mode and GRDH format was acquired from the Sentinel Scientific Data Hub [63] and preprocessed using the free and open source Sentinel Application Platform (SNAP) which includes a collection of Sentinel-1 specific processing tools. The first steps in the preprocessing consisted in applying an orbit file using restituted orbits and removal of thermal noise. In a next step radiometric calibration was performed to convert intensity values to the backscatter coefficient sigma naught. Finally, terrain correction was performed with the Shuttle Radar Topography Mission (SRTM) $30 \mathrm{~m}$ resolution data to correct for layover and foreshortening effects. Depending on the total number of available acquisitions in the respective orbit directions (see Table 2), data in either ascending or descending mode were selected and transformed into a data cube for the subsequent analysis. A detailed description of the applied methodology is presented in Figure 6.

Table 2. Available Sentinel-1A IW GRDH scenes for the study areas.

\begin{tabular}{ccc}
\hline S-1 Data Product & \multicolumn{2}{c}{ Sentinel-1A, GRDH, IW, 10 m } \\
\hline acquisition period & 1 September 2014-30 September 2016 \\
polarization mode & \multicolumn{2}{c}{ dual (VH/VV) } \\
orbit direction & ascending & descending \\
Mekong Delta & $(0)$ & 192 \\
Red River Delta & $(33)$ & 83 \\
Pearl River Delta & 174 & $(8)$ \\
Yellow River Delta & $(19)$ & 66 \\
\hline
\end{tabular}




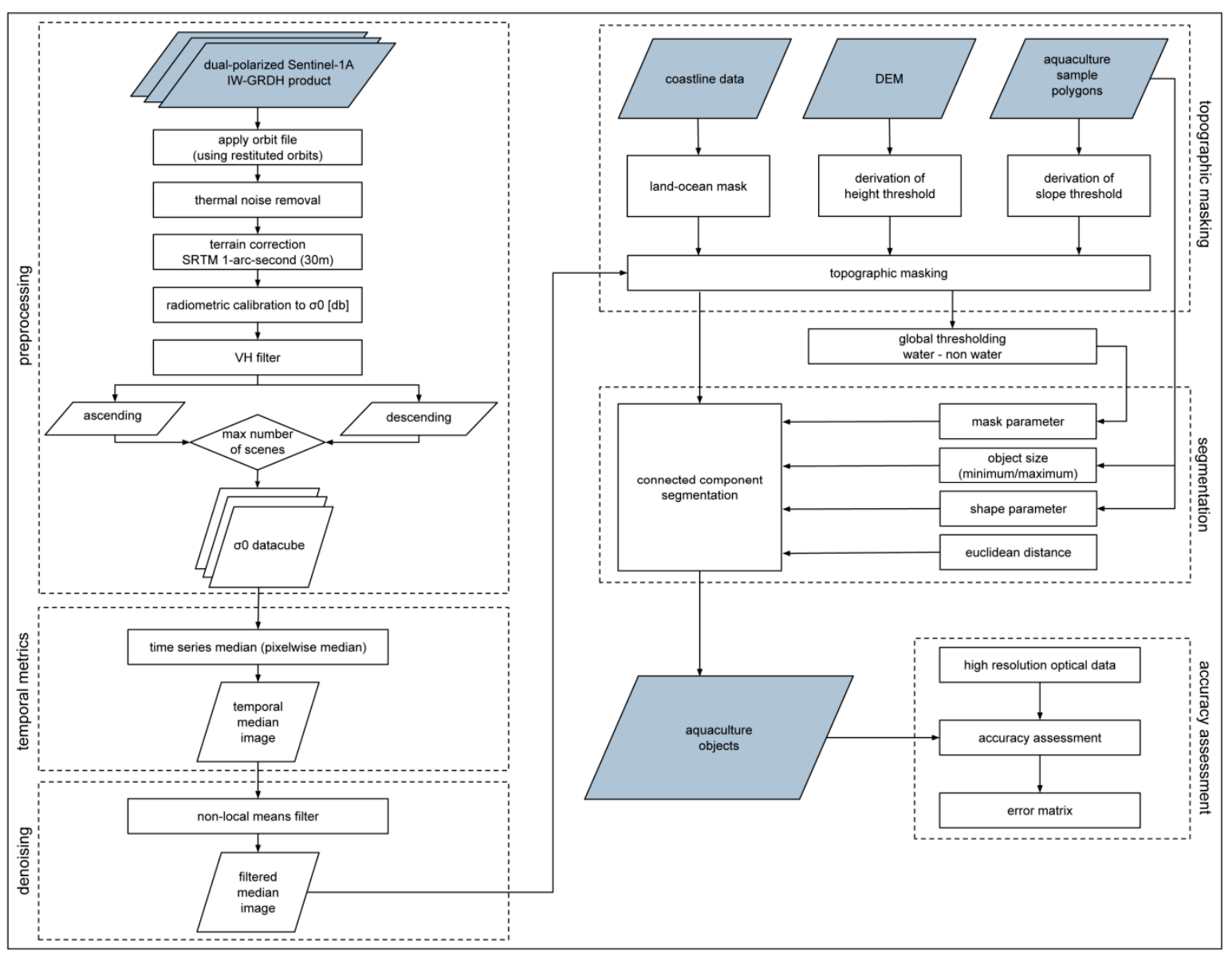

Figure 6. Workflow of the applied method.

\subsection{Derivation of $S A R$ Temporal Metrics}

The quality of SAR images is influenced by speckle, a signal dependent granular noise, making it difficult to achieve good segmentation results. The appearance of narrow, elongated line structures such as dams and levees is crucial for the mapping of aquaculture on a single pond level. Therefore, the presence of speckle is a main drawback in SAR images because the intensity data are deteriorated by multiplicative noise which strongly influences the detection of lines and line structures as a basis to identify ponds $[64,65]$.

Since many Sentinel-1 images are available for the study sites (see Table 2), we were able to analyze the time series of the sigma naught values of each pixel. Aquaculture, as an enclosed standing water body, has distinct temporal characteristics in the SAR time series with low backscatter values throughout the year. The pixel-wise median was calculated for the time series data cube to reduce speckle noise and identify permanent and stable low scatterers from the dense and long temporal time series. We chose the median of all observations rather than the mean to describe a single and most typical backscatter value because of the strong influence of possible extreme outliers on mean values [66]. By averaging over time the median of the temporal image stack (data cube) enables a reduction of speckle noise but also improves the detection of very narrow surface features such as dams and levees surrounding aquaculture ponds. Figure 7 depicts samples of single-date Sentinel-1 radar imagery (Figure $7 \mathrm{~b}, \mathrm{e}, \mathrm{h}$ ) and shows how speckle is reduced noticeably (Figure 7c,f,i) when pixel wise temporal median is applied to the time series data cube. Computing a pixel wise median for the multi-temporal data cube strongly reduced speckle noise effects and resulted in a smoothed image but effectively improved the recognition of small structures (see Figure 7). 

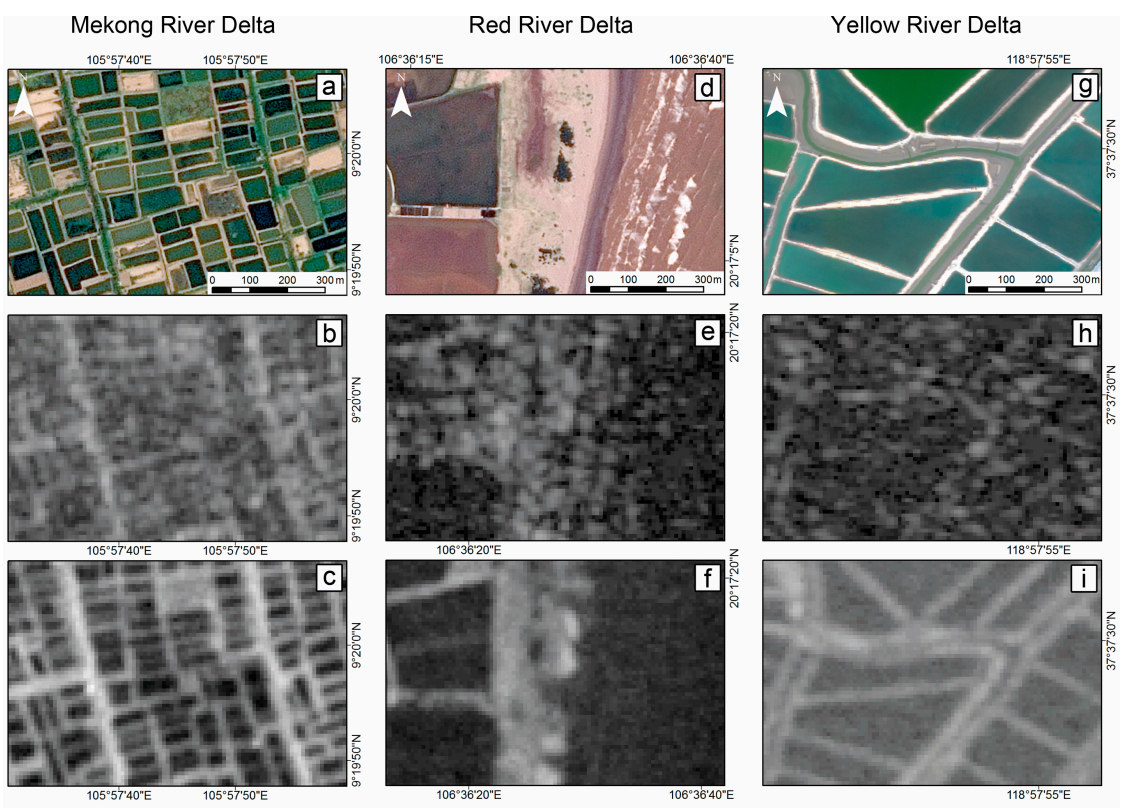

Figure 7. Appearance of aquaculture ponds in high resolution optical data $(\mathbf{a}, \mathbf{d}, \mathbf{g})$; single scenes of Sentinel-1A $(\mathbf{b}, \mathbf{e}, \mathbf{h})$; and the smoothed median times series of Sentinel-1A data: $(\mathbf{c}, \mathbf{f}, \mathbf{i})$ for the Mekong Delta (1); Red River Delta (2); and the Yellow River Delta (3). Image source: (a) SPOT-6 date: 10 February 2015; (d) SPOT-6, 30 May 2015; and (g) WorldView-2 date: 20 September 2012.

Figure 8 shows the histogram of the calculated temporal median image based on the available Sentinel-1 time series stack for all study areas in VH (vertical transmitting, horizontal receiving) and VV (vertical transmitting, vertical receiving) polarization. For co-polarization mode, the range of backscattering intensity values in $\mathrm{dB}$ is wider than cross-polarization mode and is about $-43 \mathrm{~dB}$ to $2 \mathrm{~dB}$. Both VH and VV polarization mode are suitable to detect water as well as aquaculture ponds since we found that demarcation of land and water surfaces is quite similar in these two modes. We tested the suitability to detect water and aquaculture in VH and VV polarized data and we achieved good results for both of them. We used the $\mathrm{VH}$ median stack since its distribution of backscatter values in the histogram showed two distinct peaks in all study sites and can be considered largely bimodal, whereas for $\mathrm{VV}$ the peaks are less pronounced. In a later step, we applied a water threshold algorithm which is suited for the separation of bimodal distributions $[67,68]$.
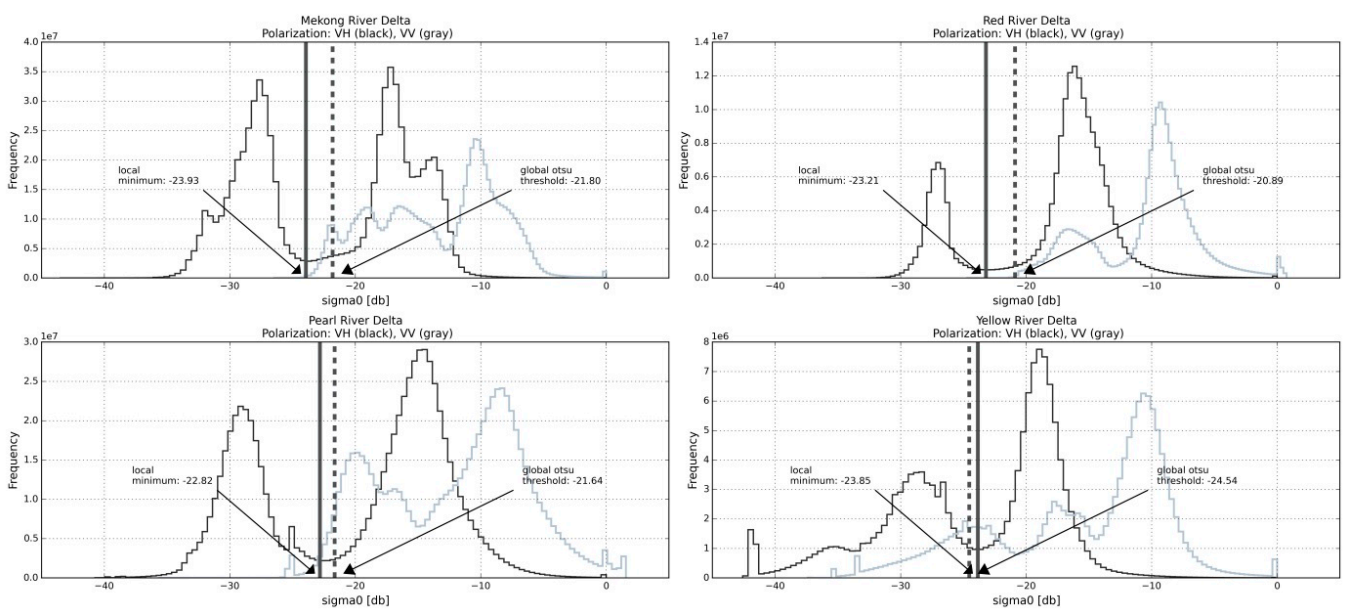

Figure 8. Histogram based on the smoothed (median) Sentinel-1A time series for cross-polarized VH (black lines) and co-polarized VV (grey lines) data. 


\subsection{Edge Sharpening}

We tested and compared the effect of different denoising methods on image quality for small subsets gained from the large temporal median image (see Figure 9): the non-local means denoising [69-72], total variation chambolle [73], total variation bregman [74], and bilateral filter [75]. On the basis of visual perception, we considered the bilateral denoising and non-local means filter as the most suitable methods for sharpening the linear details such as dikes and levees located between adjoining ponds and improve the identification of single ponds. Local smoothing methods select samples within a local window and aim at a noise reduction but are weak in preserving fine structure, details and texture [76]. The Non-local means filter however, is capable of strong noise reduction while preserving details $[69,71]$. We applied a fast version of the non-local means algorithm implemented in the image restoration module of the Python library scikit-image [77] was used to sharpen while preserving the edges of the temporal median images covering the entire study areas.

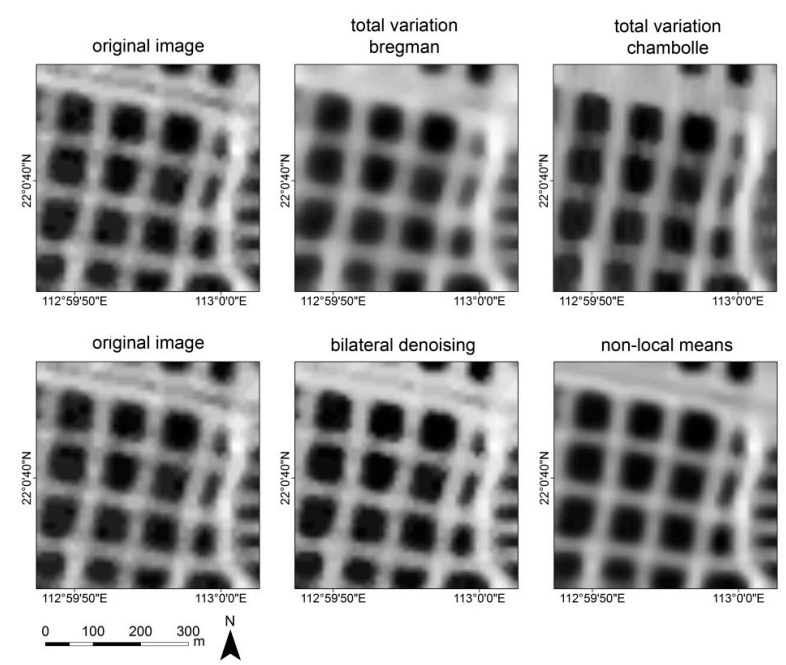

Figure 9. Results of different denoising algorithms which were tested for the temporal median image (Pearl River Delta).

\subsection{Terrain Masking}

DEM derived topographic features were used to extract areas where coastal aquaculture ponds can potentially occur. Terrain information was considered a major limiting parameter that affects the occurrence of aquaculture ponds in the low-lying coastal regions. For the aquaculture sample dataset (see Section 3.2), we extracted elevation and slope values and calculated the summary statistics (mean) of elevation and slope for each aquaculture pond using the Python module rasterstats. The purpose of the extraction of topographic features based on pond vector geometries was to obtain threshold values relating to terrain information. We used thresholds defined as the lowest slope as well as maximum height in order to generate the topographic masks (height mask and slope mask).

Terrain masking based on DEM features and coastline data was also performed to exclude ocean, rivers and water bodies which are most likely to be confused with aquaculture ponds, such as small mountain lakes or reservoirs located in higher latitudes. Therefore, most water bodies in mountain area were removed by the elevation threshold. Terrain relief causes geometric terrain distortions such as overlay, foreshortening and shadow effects and may lead to problems in the interpretation of SAR imagery [78]. Relief features with steep slopes such as mountains can cause shadows in the down range dimension of SAR images and lead to confusion in discriminating radar shadows from water bodies because both result in low backscatter values and appear in dark [79]. Steep slope areas were also removed in order to eliminate radar shadows and relief with low probability of water and consequently aquaculture. 


\subsection{Segmentation}

Our goal was to develop an approach exclusively based on open source tools for the purpose of increased flexibility and transferability enabling regional, continental and global processing. Clewley et al. [80] and Bunting et al. [81] reviewed different open-source segmentation tools, such as RSGISLib, InterIMAGE, OpenCV, scikit-image and OTB. For the object based analyses of the Sentinel-1 image data cubes, we used the Connected Component Segmentation algorithm provided within the Orfeo Toolbox (OTB). OTB is an open source library of image processing algorithms [82], initiated and funded by the French Space Agency (CNES). The connected component segmentation is accessible in OTBs users interface, QGIS, Python, the command line or C++ and is based on the Insight Segmentation and Registration Toolkit [83], a medical image processing library.

\subsubsection{Derivation of Water Thresholds}

Prior to the segmentation, different water thresholds were tested in order to derive suitable mask parameters for the discrimination of water and land area. Thresholds were used as parameters to be set for the calculation of a water mask as a preliminary step of the subsequent connected component segmentation. The following water thresholding methods were investigated: Isodata [84], Li [85], Yen [86], Otsu [68], and Adaptive thresholding [87]. These methods are also included in the open source Python library scikit-image [87]. For a closer look at the performance of the tested thresholding methods, we extracted two smaller subsets with a size of $10 \mathrm{~km} \times 10 \mathrm{~km}$ for each study site (see Figure 10). We found the Otsu method the best performing of the five threshold methods in terms of separation of the pond water surfaces and surrounding land area (dikes, levees, and dams) and was therefore selected as an appropriate thresholding method for the water mask generation as part of the subsequent connected component segmentation. The Otsu method is used to automatically perform a clustering-based image thresholding [68] and assumes that the image contains two classes of pixel which fits well to the already referred (see Section 3.2) distinct bimodal distribution of backscatter intensity values in cross-polarization $(\mathrm{VH})$ of the temporal median images.
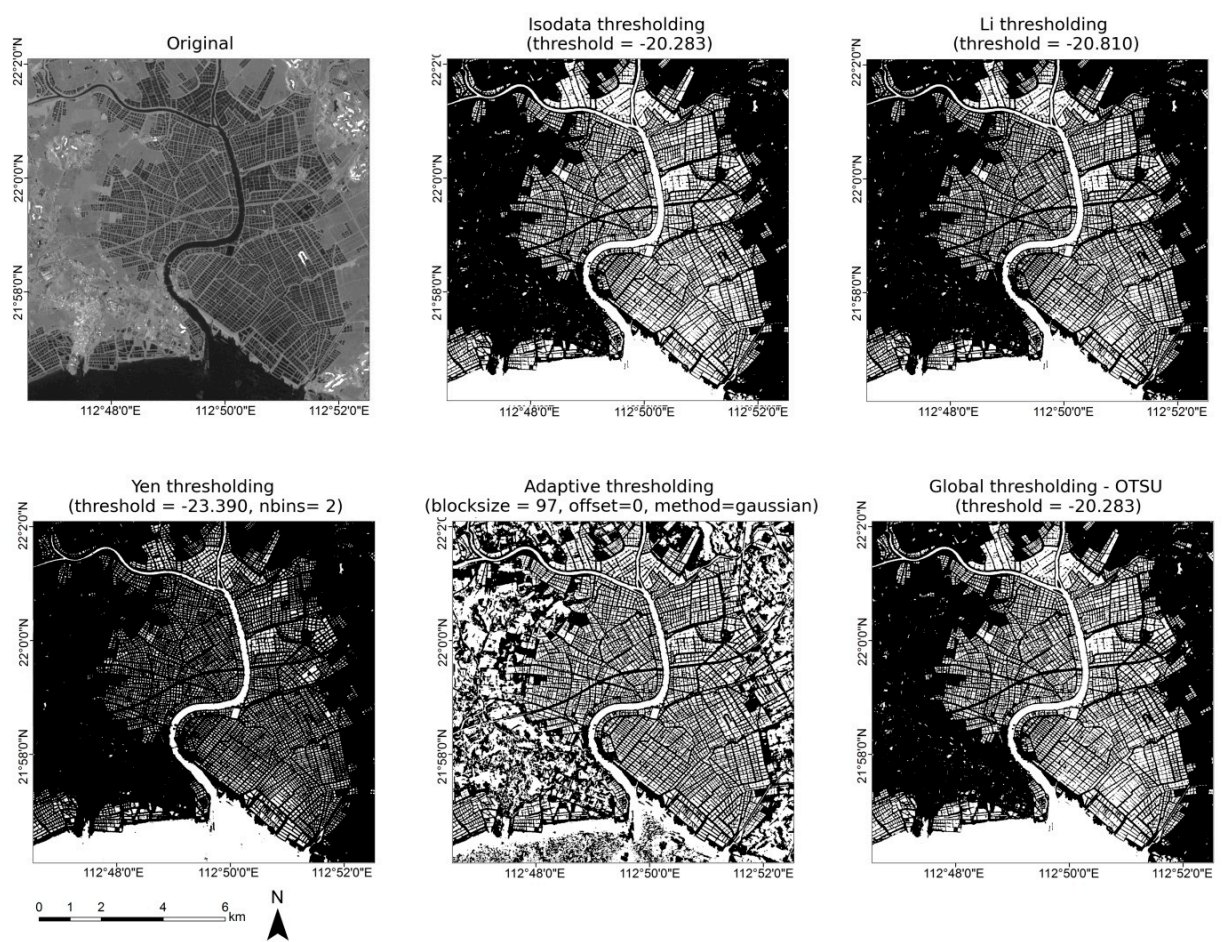

Figure 10. Binary images resulting from the thresholding methods. Example spot from the Pearl River Delta, China. 


\subsubsection{Connected Component Segmentation}

We performed a connected component segmentation labeling the objects in a binary image. First, the threshold defined by the Otsu method was used to build a binary mask to select pixels of the image which will be segmented (potential aquaculture sites) thereby reducing image data volume and computing time. In a second step, a Euclidian intensity pixel distance criterion was defined to calculate the distance between two neighboring pixels and determining whether they are considered to belong to the same segment. We iteratively calculated different distance criterion values to test how they influence the results. After this segmentation step, object and shape properties were derived from the aquaculture samples (see Section 3.2) to select appropriate criterions for an object based image filtering. Object area (minimum and maximum), object elongation, and the region ratio (size of the bounding box and the real size of the object) were applied and the vectorized output of the object based image filtering was exported to shapefile format.

\subsection{Validation}

For each study area we created a reference dataset including two classes-aquaculture and non-aquaculture. All surface features that were not labeled as aquaculture during the segmentation were classified as non-aquaculture. A total of 200 sample points per class were distributed for each study area by stratified random sampling [88]. In order to provide a statistical sound validation basis, a geo-referenced vector grid of $5 \times 5$ squares was aligned to the extent of the respective study area and for each cell the proportion of aquaculture class was calculated. Based on the grid cell's share of the aquaculture area in each tile in relation to the total aquaculture area we distributed the 200 aquaculture and 200 non-aquaculture points. Reference data were derived by multiple expert analysts who labeled each sample point with aquaculture or non-aquaculture based on ground truth data, very high resolution WorldView-2/3, Quickbird-2, Ikonos-2, and SPOT-5/ 6 data available for some coastal parts and images acquired between 2014 and 2016 available through Google Earth for the remaining areas. To assess the accuracy of the aquaculture mapping, a confusion matrix was calculated for each study area and standard performance measures, i.e., overall accuracy, producer's and user's accuracy were derived from the matrix.

\section{Results}

\subsection{Validation Results}

We computed the accuracies for the two classes for each study site separately. The user's and producer's accuracy (UA and PA) and the overall accuracy (OA) were calculated as defined in [88] to quantify the agreement between the SAR-based mapping and a reference dataset (see Table 3 and Figure 11). The PA is meant for the ratio of the total number of correct samples in a given class by the total number of samples of that class as indicated by the reference data. The UA is produced by dividing the total number of correct sample of a class by the total number of sample units as classified in the segmentation result [88]. The OA indicates the overall agreement between the SAR-based mapping and the reference data. For the Mekong Delta we correctly classified 166 of 200 aquaculture points and 169 of 200 non-aquaculture points. In the Yellow River Delta, we achieved 149 out of 200 correctly classified aquaculture points. For the study areas in China, we correctly classified 171 of 200 and 146 of 200 aquaculture points for the Pearl River Delta and Yellow River Delta, respectively. The calculated overall accuracies from the error matrices of the four coastal study sites account for 0.83 for the Mekong Delta, 0.84 for the Red River Delta, 0.88 for the Pearl River Delta, and 0.80 for the Yellow River Delta (see Table 3). The segmentation results presented similar accuracy values among the individual study areas, resulting in a mean overall accuracy of 0.83 . 

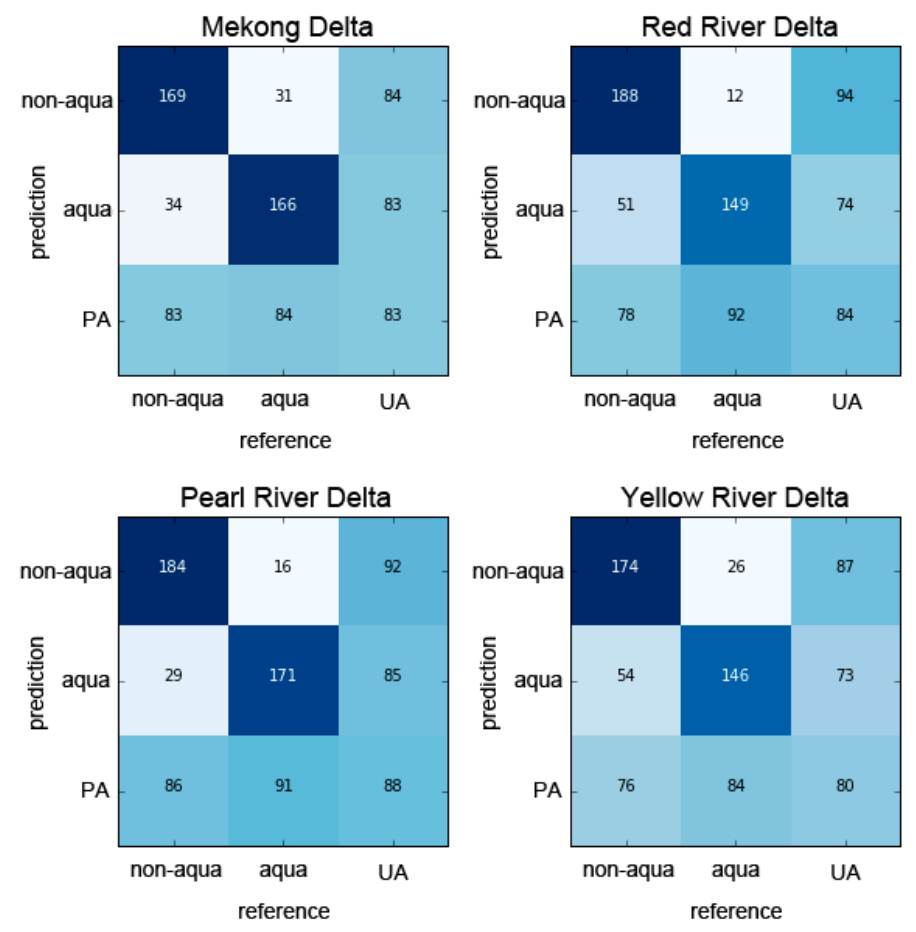

Figure 11. Detailed quantities of the accuracy assessment for the four study sites. Error matrices for the two classes aquaculture (aqua) and non-aquaculture (non-aqua).

Table 3. Accuracy assessment for the two classes aquaculture and non-aquaculture per study site. Producer's accuracy (PA), user's accuracy (UA) and overall accuracy (OA).

\begin{tabular}{|c|c|c|c|c|c|c|}
\hline \multirow{2}{*}{ Study Area } & \multicolumn{2}{|r|}{ PA } & \multicolumn{2}{|c|}{ UA } & \multirow{2}{*}{ OA } & \multirow{2}{*}{ Kappa } \\
\hline & Aquaculture & Non-Aquaculture & Aquaculture & Non-Aquaculture & & \\
\hline Mekong Delta & 0.84 & 0.83 & 0.83 & 0.84 & 0.83 & 0.67 \\
\hline Red River Delta & 0.92 & 0.78 & 0.74 & 0.94 & 0.84 & 0.68 \\
\hline Pearl River Delta & 0.91 & 0.86 & 0.85 & 0.92 & 0.88 & 0.77 \\
\hline Yellow River Delta & 0.84 & 0.76 & 0.87 & 0.73 & 0.80 & 0.59 \\
\hline
\end{tabular}

\subsection{Aquaculture Mapping Evaluation for the Four Study Areas}

The results of the aquaculture mapping for the four selected coastal study areas are presented in Figures 12 and 13. The aquaculture mapping product for each delta is paired with two overview maps showing shaded relief derived from digital elevation model (DEM) for the entire river delta area and a more detailed overview of the temporally averaged Sentinel-1 median image illustrating the geographic location of the respective $10 \mathrm{~km} \times 10 \mathrm{~km}$ large exemplary coastal spots (outlined in red). We acknowledge that two coastal spots represent a small proportion of the respective study sites which cover an area of several thousand square kilometers (see Table 4). Due to the small object size of the ponds, it is difficult to display the entire object-based mapping result for one complete study area and we focused on some exemplary coastal spots located along the deltas' shorelines in the transition zone of water and land area. When comparing the mapping result to the related SAR image product we can clearly see the spatial distribution and extent of aquaculture in the study areas. In the SAR data, aquaculture appears in dark color as a result of the low backscatter intensity values and the respective mapped aquaculture objects illustrated in blue color. The connected component algorithm however failed to detect all segments, for instance very small ponds as can be seen in Figure 12 (M2). 
Table 4. Extent of predicted aquaculture for the four river delta areas in this study.

\begin{tabular}{ccc}
\hline Study Area & Total Area $\mathbf{( k m}^{2} \mathbf{)}$ & Aquaculture Area (ha) \\
\hline Mekong Delta & 39,385 & 265,943 \\
Red River Delta & 15,541 & 29,940 \\
Pearl River Delta & 42,378 & 105,070 \\
Yellow River Delta & 7435 & 86,371 \\
\hline
\end{tabular}
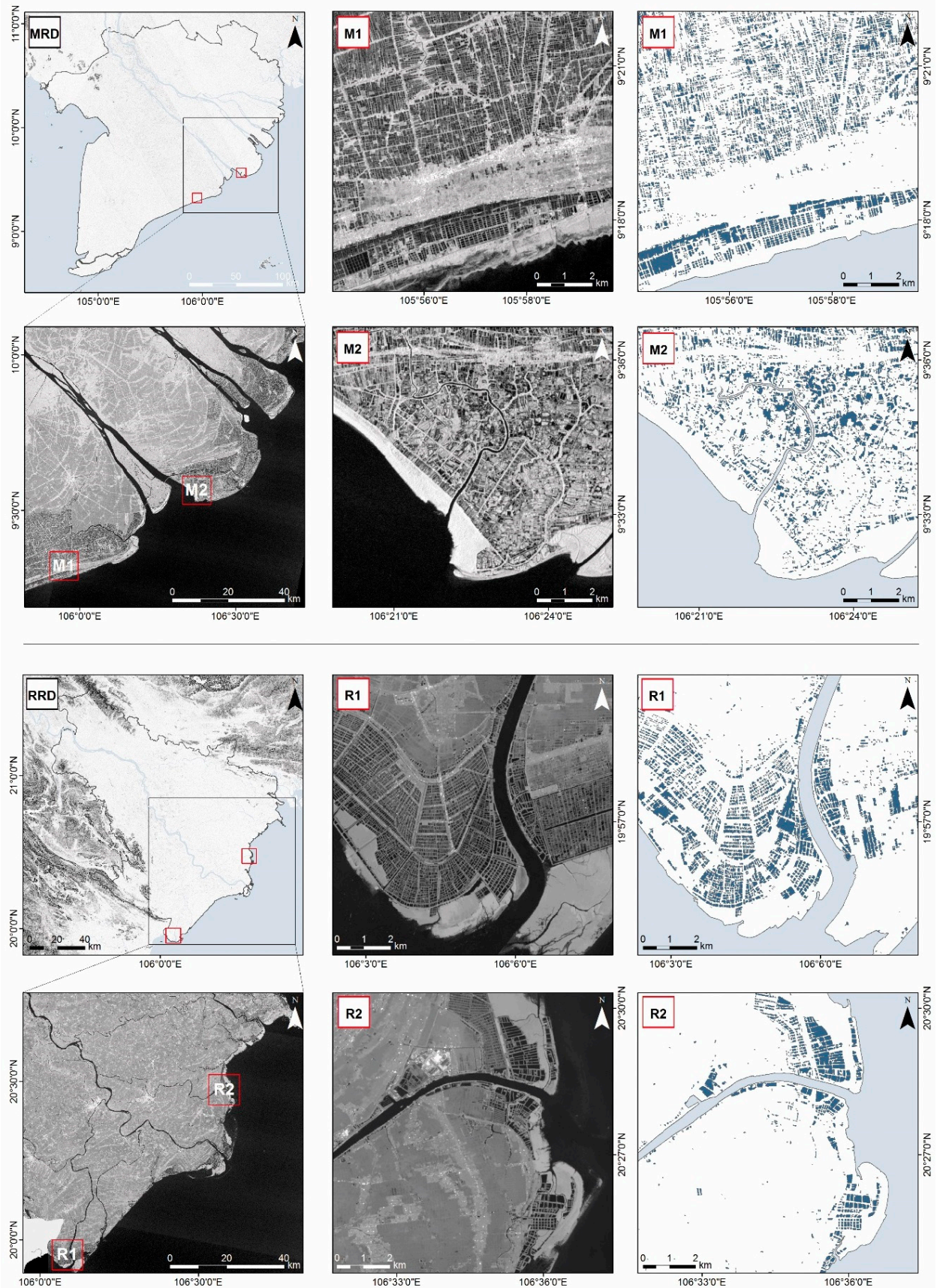

Figure 12. Mapped aquaculture in the Mekong Delta (MRD) for two $100 \mathrm{~km}^{2}$ large coastal spots (M1,M2). Mapped aquaculture in the Red River Delta (RRD) for two $100 \mathrm{~km}^{2}$ large coastal spots $(\mathbf{R} 1, \mathbf{R} 2)$. Each of the coastal spots is displayed twice, showing the temporal median image and the respective aquaculture mapping result. 

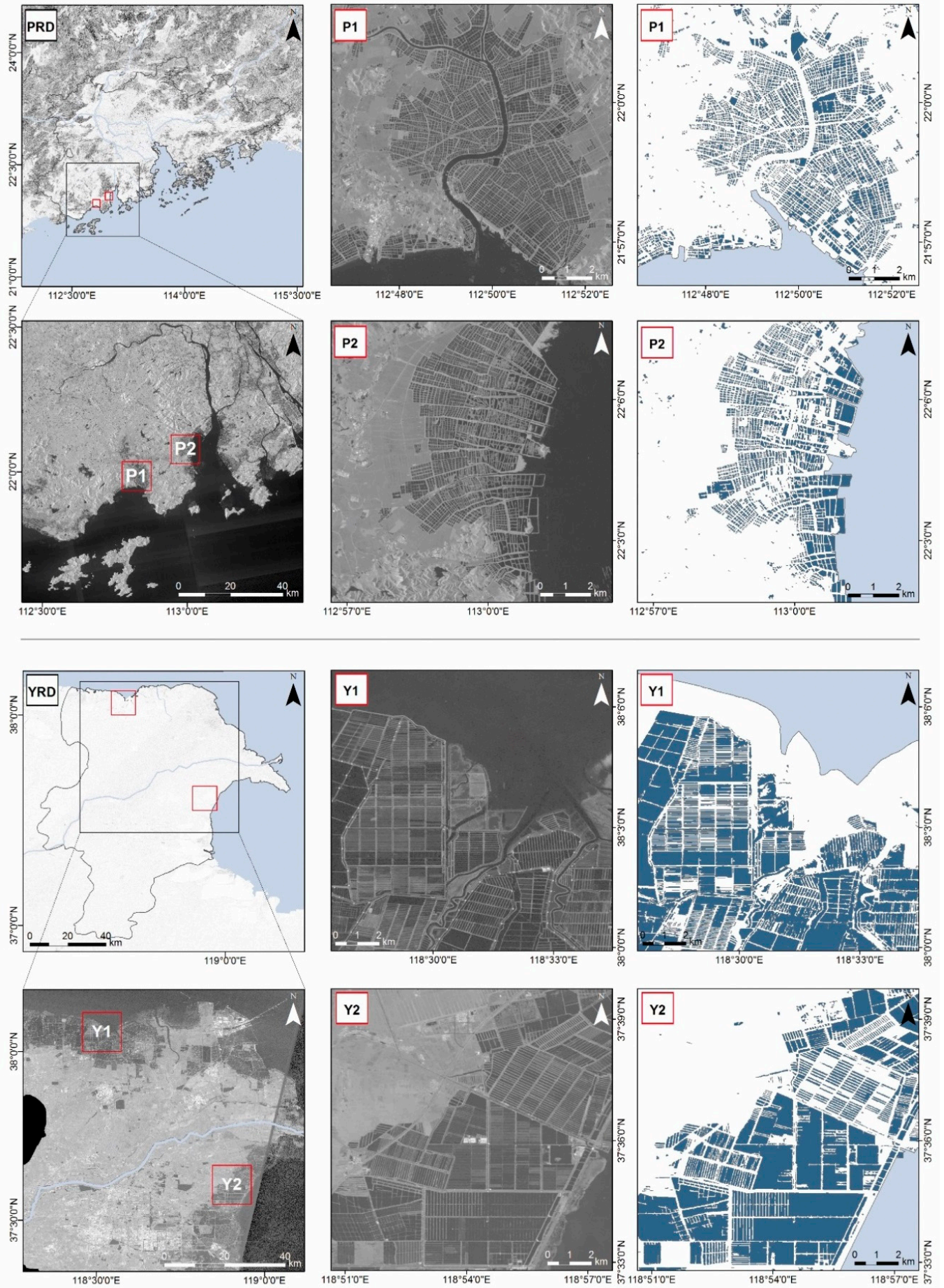

Figure 13. Mapped aquaculture in the Pearl River Delta (PRD) for two $100 \mathrm{~km}^{2}$ large coastal spots (P1,P2). Mapped aquaculture in the Yellow River Delta (YRD) for two $100 \mathrm{~km}^{2}$ large coastal spots $(\mathbf{Y 1}, \mathbf{Y} 2)$. Each of the coastal spots is displayed twice, showing the temporal median image and the respective aquaculture mapping result.

\section{Discussion}

A novel aquaculture mapping approach has been developed using time series of high spatial resolution Synthetic Aperture Radar and an open source segmentation algorithm which we applied to major coastal river deltas in China and Vietnam. The presented method has two major advantages: a key feature of our approach is the use of open source tools and free and open remote sensing data 
as well as its ability to integrate other preprocessing or segmentation algorithms into the framework. In general, the methodology that has been followed is valid for any coastal site and could be transferred to other geographic regions around the globe. This method enables mapping and investigation of aquaculture for entire coastal zones could be on a continental or global scale.

The mapping quality of aquaculture ponds with SAR data depends on the minimum detectable size of dikes, dams, or levees surrounding the ponds and their specific surface materials and properties influencing the detection capability. A finer spatial resolution can increase the appearance of narrow elongated line structures and with it allow for a better detection of edges surrounding a pond. This is a major advantage and results in improved separation of the pond water surface and its bordering dike, dam or levee. The spatial resolution of Sentinel-1, requires aquaculture ponds to be of a certain size in order to detect and recognize their outlines of a pond. For large industrial ponds, as in the Yellow River Delta in China, the spatial resolution of Sentinel-1 is adequate and does not pose a problem for our method. In regions with mainly extensive, smallholder aquaculture, such as the Mekong Delta in Vietnam, pond sizes are small and spatial resolution is a clear limiting factor.

The effect of spatial resolution on the object shape is another issue and a crucial criterion for the selection of appropriate segmentation parameters. The rectangular and compact shapes of aquaculture ponds are a defining feature for the differentiation between natural standing water bodies and managed aquaculture water bodies. Outlines of ponds may be lost if the enclosing dams, dikes, or levees are smaller than the spatial resolution with the effect that neighboring ponds form large, irregularly shaped objects, which are difficult to identify as aquaculture in the SAR image. Apart from the challenges that come with the identification of aquaculture in radar imagery, it must be made clear that in the context of aquaculture assessment, SAR sensors demonstrate clear benefits over optical remote sensing instruments for continuous mapping capabilities in the coastal zone [32].

A key advantage of SAR imaging are permanent observation capabilities since radar waves can operate independent from weather conditions, cloud coverage and time of day. Cloud cover is a prevailing issue in optical remote sensing in the context of aquaculture mapping, which limits the ability to derive full area coverages of aquaculture from high resolution commercial optical sensors such as SPOT, IKONOS, RapidEye, WorldView or Quickbird. For a consistent mapping of aquaculture in tropical regions with frequent cloud cover (e.g., the Mekong Delta as demonstrated by [89]), we cannot rely on using only optical sensors. Moreover, acquiring multi-temporal data from these sensors is cost-intensive and data continuity might be limited to tasking orders.

Another basic precondition for accurate mapping is the availability of a sufficient number of satellite data acquisitions to create time series. Dense SAR time series are needed to distinguish aquaculture ponds, as relatively stable water bodies from temporary water bodies. This is a major issue for many coastal areas and specifically river deltas, where floodplains or paddy rice fields might be confused with aquaculture if the temporal resolution of the time series is inadequate to depict hydrological characteristics and seasonality of land cover other than aquaculture.

Sentinel-1 is currently the only operational satellite mission that offers free access to continuous, timely and routine SAR data. For the first time we can use dense SAR time series at such high spatial resolution, recorded at wide swaths, which provide huge potential for large scale and even global assessment of aquaculture ponds. For some areas, data coverage of Sentinel-1 is still low and insufficient or available acquisitions might not be adequately distributed throughout a year. However, as the recent launch of Sentinel-1B completed the two-pair SAR mission of the Copernicus program, advanced mapping capabilities arise from improved data coverage, timeliness and data availability. As stated by the European Space Agency (ESA), a central goal of the Sentinel-1 mission is to assure C-Band SAR data continuity. In this regard, Sentinel-1 builds on the successful C-band SAR missions of ESA's ERS-1, ERS-2 and Envisat-ASAR. Two further SAR satellites (Sentinel-1C and 1D) will be launched starting in 2021 as follow-on to the current project and for the intended purpose of producing of a consistent, long-term data archive. 
New opportunities for the mapping and monitoring of aquaculture will arise from the use of different sensors. Combining high resolution SAR and optical satellite time series, for example data acquired by the Sentinel- 1 and Sentinel- 2 constellations, offers great potential for precise mapping of aquaculture ponds and will build the basis for a wide field of aquaculture applications, be it water quality monitoring or environmental impact assessment.

We recognize that accuracy could be improved by using refined edge detection methods able to enhance linear structures (pond boundaries), hence improving the representation of aquaculture objects in the SAR imagery. New methods could be developed to increase the detection of single ponds and reduce possible under- or overestimation of aquaculture pond areas. However, it was our goal in this study to have a general, adaptable approach able to achieve good mapping results for large-scale areas rather than one based on handling very small test cases.

\section{Conclusions}

We presented a novel approach to assess coastal aquaculture at large spatial scales using earth observation time series. Rising demand and international trade has driven the rapid expansion of aquaculture with a remarkably increase from 20 million tons in 1994 to 74 million tons produced in 2014. Asia generates 90 percent of the total global aquaculture volume which is mainly produced by pond systems in fertile coastal environments.

Since cloud cover is not a limiting factor for Synthetic Aperture Radar sensors, they demonstrate great potential for continuous mapping and monitoring of coastal aquaculture, particularly in cloud-prone tropical and sub-tropical zones. In line with the Copernicus program, the European Space Agency provides free and open data access to its Sentinel-1 mission, which is designed for frequent and systematic data acquisition with high spatial resolution and wide area coverage.

We developed a framework that analyzes the large volume of data acquired by the recently launched Sentinel-1A radar imaging satellite to assess aquaculture in four river delta hotspots along the coastal zone of China and Vietnam. In our approach, we processed more than 500 Sentinel-1A scenes for a two-year period with a data volume of more than 700 GB to create temporally smoothed time series which we applied as a basis for a subsequent connected component segmentation to obtain aquaculture pond objects. Our results show that we were able to assess coastal aquaculture with a mean average overall accuracy of 0.83 for the four study areas.

Using freely available satellite and auxiliary data, and open source processing software and tools, we developed a method that benefits from the flexibility of being able to be easily transferable and scalable to analyze aquaculture for entire coasts at any location on the globe. For the very first time, satellite remote sensing has been used for large-scale assessment of coastal aquaculture for entire river delta regions-as demonstrated in this study for the Mekong, Red River, Pearl River and Yellow River deltas. Our method can be used as a basis for an assessment of aquaculture ponds for the entire coastal area of Asia or global scale.

Acknowledgments: This work was partially funded by the German Ministry of Education and Research (BMBF) through the DeltAdapt project. The authors would also like to thank the ESA for providing free access to Sentinel-1 radar data; the USGS for providing the free global SRTMGL1 1 arc second data; the IGSNRR for the high resolution coastline dataset; and CNES for developing and providing the open source tool OTB.

Author Contributions: C.K. and M.O. designed the research concept. M.O. processed and analyzed the data. K.C. helped with the data processing. All authors jointly discussed the results. M.O. authored the first version of the manuscript, and C.K. and K.C. worked on successive versions of the manuscript.

Conflicts of Interest: The authors declare no conflict of interest.

\section{Appendix A}

Software packages used for reading the spatial data, processing it and assessing aquaculture ponds with an object based method (segmentation): 
- $\quad$ Python 2.7.11

- Scipy 0.17.0

- GDAL 1.11.2

- numpy 1.10.4

- $\quad$ scikit-image 0.12 .3

- $\quad$ scikit-learn 0.17.1

- rasterstats 0.10 .03

- rasterio $1.0 \mathrm{a} 3$

- $\quad$ Fiona 1.7.1

- pandas 0.18.0

- Orfeo Toolbox 5.4.0

\section{References}

1. Ottinger, M.; Clauss, K.; Kuenzer, C. Aquaculture: Relevance, distribution, impacts and spatial assessments-A review. Ocean Coast. Manag. 2016, 119, 244-266. [CrossRef]

2. Food and Agriculture Organization (FAO). The State of World Fisheries and Aquaculture 2016; FAO: Rome, Italy, 2016.

3. Renaud, F.G.; Le, T.T.H.; Lindener, C.; Guong, V.T.; Sebesvari, Z. Resilience and shifts in agro-ecosystems facing increasing sea-level rise and salinity intrusion in Ben Tre Province, Mekong Delta. Clim. Chang. 2014, 133, 1-16. [CrossRef]

4. Cao, L.; Wang, W.; Yang, Y.; Yang, C.; Yuan, Z.; Xiong, S.; Diana, J. Environmental Impact of Aquaculture and Countermeasures to Aquaculture Pollution in China. Environ. Sci. Pollut. Res. 2007, 14, 452-462.

5. Rico, A.; Van den Brink, P.J. Probabilistic risk assessment of veterinary medicines applied to four major aquaculture species produced in Asia. Sci. Total Environ. 2014, 468-469, 630-641. [CrossRef] [PubMed]

6. Kuenzer, C.; Ottinger, M.; Wegmann, M.; Guo, H.; Wang, C.; Zhang, J.; Dech, S.; Wikelski, M. Earth observation satellite sensors for biodiversity monitoring: Potentials and bottlenecks. Int. J. Remote Sens. 2014, 35, 6599-6647. [CrossRef]

7. Matgen, P.; Hostache, R.; Schumann, G.; Pfister, L.; Hoffmann, L.; Savenije, H.H.G. Towards an automated SAR-based flood monitoring system: Lessons learned from two case studies. Phys. Chem. Earth 2011, 36, 241-252. [CrossRef]

8. Little, D.C.; Karim, M.; Turongruang, D.; Morales, E.J.; Murray, F.J.; Barman, B.K.; Haque, M.M.; Kundu, N.; Belton, B.; Faruque, G.; et al. Livelihood impacts of ponds in Asia-opportunities and constraints. In Fishponds in Farming Systems; Van der Zijpp, A., Verreth, J., Van Mensvoort, M., Bosma, R., Beveridge, M., Eds.; Wageningen Academic Publishers: Wageningen, The Netherlands, 2007; pp. 177-202.

9. Henderson, F.M.; Lewis, A.J. Principles and Applications of Imaging Radar. Manual of Remote Sensing; John Wiley \& Sons Inc.: New York, NY, USA, 1998.

10. Sridhar, P.N.; Surendran, A.; Ramana, I.V. Auto-extraction technique-based digital classification of saltpans and aquaculture plots using satellite data. Int. J. Remote Sens. 2008, 29, 313-323. [CrossRef]

11. Zhang, T.; Li, Q.; Yang, X.; Zhou, C.; Su, F. Automatic Mapping Aquaculture in Coastal Zone from TM Imagery with OBIA Approach. In Proceedings of the 18th International Conference on Geoinformatics, Beijing, China, 18-20 June 2010; pp. 1-4.

12. Yang, D.; Yang, C. Detection of seagrass distribution changes from 1991 to 2006 in Xincun Bay, Hainan, with satellite remote sensing. Sensors 2009, 9, 830-844. [CrossRef] [PubMed]

13. Hazarika, M.K.; Samarakoon, L.; Honda, K.; Thanwa, J.; Pongthanapanich, T.; Boonsong, K.; Luang, K. Monitoring and Impact Assessment of Shrimp Farming in the East Coast of Thailand Using Remote Sensing and Gis. Archives 2000, XXXIII, 504-510.

14. De Graaf, G.; Kamal, M.; Martin, T.; Schepel, M. Remote Sensing Techniques for Detecting and Mapping Aquaculture Ponds in Bangladesh. In Proceedings of the Second International Symposium on GIS-Spatial Analyses in Fishery and Aquatic Sciences, Brighton, UK, 3-6 September 2002. 
15. Zhang, T.; Yang, X.; Hu, S.; Su, F. Extraction of coastline in aquaculture coast from multispectral remote sensing images: Object-based region growing integrating edge detection. Remote Sens. 2013, 5, 4470-4487. [CrossRef]

16. Disperati, L.; Virdis, S.G.P. Assessment of land-use and land-cover changes from 1965 to 2014 in Tam Giang-Cau Hai Lagoon, central Vietnam. Appl. Geogr. 2015, 58, 48-64. [CrossRef]

17. Loberternos, R.A.; Porpetcho, W.P.; Graciosa, J.C.A.; Violanda, R.R.; Diola, A.G.; Dy, D.T.; Otadoy, R.E.S. An object-based workflow developed to extract aquaculture ponds from airborne lidar data: A test case in central visayas, Philippines. ISPRS-Int. Arch. Photogramm. Remote Sens. Spat. Inf. Sci. 2016, XLI-B8, 1147-1152.

18. Virdis, S.G.P. An object-based image analysis approach for aquaculture ponds precise mapping and monitoring: A case study of Tam Giang-Cau Hai Lagoon, Vietnam. Environ. Monit. Assess. 2014, 186, 117-133. [CrossRef] [PubMed]

19. Joshi, N.; Baumann, M.; Ehammer, A.; Fensholt, R.; Grogan, K.; Hostert, P.; Jepsen, M.R.; Kuemmerle, T.; Meyfroidt, P.; Mitchard, E.T.A.; et al. A review of the application of optical and radar remote sensing data fusion to land use mapping and monitoring. Remote Sens. 2016, 8, 70. [CrossRef]

20. Kuenzer, C.; Klein, I.; Ullmann, T.; Georgiou, E.; Baumhauer, R.; Dech, S. Remote Sensing of River Delta Inundation: Exploiting the Potential of Coarse Spatial Resolution, Temporally-Dense MODIS Time Series. Remote Sens. 2015, 7, 8516-8542. [CrossRef]

21. Pekel, J.-F.; Cottam, A.; Gorelick, N.; Belward, A.S. High-resolution mapping of global surface water and its long-term changes. Nature 2016, 540, 1-19. [CrossRef] [PubMed]

22. Schmitt, A.; Wendleder, A.; Roth, A.; Brisco, B. Water extent monitoring and water level estimation using multi-frequency, multi-polarized, and multi-temporal SAR data. In Proceedings of the IEEE International Geoscience and Remote Sensing Symposium, Quebec City, QC, Canada, 13-18 July 2014.

23. Ding, X.; Li, X. Monitoring of the water-area variations of Lake Dongting in China with ENVISAT ASAR images. Int. J. Appl. Earth Obs. Geoinf. 2011, 13, 894-901. [CrossRef]

24. Bertram, A.; Wendleder, A.; Schmitt, A.; Huber, M. Long-Term Monitoring of Water Dynamics in the Sahel Region Using the Multi-Sar-System. Int. Arch. Photogramm. Remote Sens. Spat. Inf. Sci. 2016, XLI-B8, 12-19.

25. Santoro, M.; Wegmüller, U. Multi-temporal synthetic aperture radar metrics applied to map open water bodies. IEEE J. Sel. Top. Appl. Earth Obs. Remote Sens. 2014, 7, 3225-3238. [CrossRef]

26. Pulvirenti, L.; Chini, M.; Pierdicca, N.; Guerriero, L.; Ferrazzoli, P. Flood monitoring using multi-temporal COSMO-SkyMed data: Image segmentation and signature interpretation. Remote Sens. Environ. 2011, 115, 990-1002. [CrossRef]

27. Schumann, G.; Matgen, P.; Hoffmann, L.; Hostache, R.; Pappenberger, F.; Pfister, L.; Carlo-based, M. Deriving distributed roughness values from satellite radar data for flood inundation modelling. J. Hydrol. 2007, 334, 96-111. [CrossRef]

28. Martinis, S.; Twele, A.; Voigt, S. Unsupervised extraction of flood-induced backscatter changes in SAR data using markov image modeling on irregular graphs. IEEE Trans. Geosci. Remote Sens. 2011, 49, 251-263. [CrossRef]

29. Martinis, S.; Kuenzer, C.; Wendleder, A.; Huth, J.; Twele, A.; Roth, A.; Dech, S. Comparing four operational SAR-based water and flood detection approaches. Int. J. Remote Sens. 2015, 36, 3519-3543. [CrossRef]

30. Kuenzer, C.; Guo, H.; Huth, J.; Leinenkugel, P.; Li, X.; Dech, S. Flood Mapping and Flood Dynamics of the Mekong Delta: ENVISAT-ASAR-WSM Based Time Series Analyses. Remote Sens. 2013, 5, 687-715. [CrossRef]

31. Gstaiger, V.; Huth, J.; Gebhardt, S.; Wehrmann, T.; Kuenzer, C. Multi-sensoral and automated derivation of inundated areas using TerraSAR-X and ENVISAT ASAR data. Int. J. Remote Sens. 2012, 33, 7291-7304. [CrossRef]

32. Kuenzer, C.; Guo, H.; Schlegel, I.; Tuan, V.Q.; Li, X.; Dech, S. Varying scale and capability of Envisat ASAR-WSM, TerraSAR-X Scansar and TerraSAR-X Stripmap data to assess urban flood situations: A case study of the mekong delta in Can Tho province. Remote Sens. 2013, 5, 5122-5142. [CrossRef]

33. Amitrano, D.; Martino, G.; Iodice, A.; Mitidieri, F.; Papa, M.N.; Riccio, D.; Ruello, G. Sentinel-1 for Monitoring Reservoirs: A Performance Analysis. Remote Sens. 2014, 6, 10676-10693. [CrossRef]

34. Herman, V.W.G.; Carlos, S.S. First Analyses of Sentinel-1 Images for Maritime Surveillance; Publications Office of the European Union: Luxembourg, 2014.

35. Marini, Y.; Emiyati; Prayogo, T.; Hanzah, R.; Hasyim, B. Fishpond aquaculture inventory in Maros Regency of South Sulawesi Province. Int. J. Remote Sens. Earth Sci. 2013, 10, 25-35. 
36. Boivin, T.G.; Dean, A.M.; Werle, D.W.; Johnston, E.; Bruce, G.S.; Suvanachai, P.; Tsui, O. Earth Observation Opportunities in the Fisheries and Aquaculture Sectors. In Proceedings of the 2004 Envisat \& ERS Symposium, Salzburg, Austria, 6-10 September 2004.

37. Travaglia, C.; Profeti, G.; Aguilar-Manjarrez, J.; Lopez, N.A. Mapping Coastal Aquaculture and Fisheries Structures by Satellite Imaging Radar; FAO Fisheries Technical Paper: Rome, Italy, 2004.

38. Szuster, B.W.; Steckler, C.; Kullavanijaya, B. Detecting and Managing Coastal Fisheries and Aquaculture Gear Using Satellite Radar Imagery. Coast. Manag. 2008, 36, 318-329. [CrossRef]

39. Chen, Y.; He, X.; Wang, J.; Xiao, R. The Influence of Polarimetric Parameters and an Object-Based Approach on Land Cover Classification in Coastal Wetlands. Remote Sens. 2014, 6, 12575-12592. [CrossRef]

40. Travaglia, C.; Kapetsky, J.; Profeti, G. Inventory and Monitoring of Shrimp Farms in Sri Lanka by ERS-SAR Data; Environment and Natural Resources Working Paper: Rome, Italy, 1999; Volume 1999.

41. Food and Agriculture Organization (FAO). The State of World Fisheries and Aquaculture 2014; FAO: Rome, Italy, 2014.

42. Food and Agriculture Organization (FAO). Fisheries and Aquaculture Software. FishStat-Software for Fishery Statistical Time Series; Fisheries and Aquaculture Department: Rome, Italy, 2011.

43. Kuenzer, C.; Renaud, F. Climate and Environmental Change in River Deltas Globally: Expected Impacts, Resilience, and Adaption. In The Mekong Delta System—Interdisciplinary Analyses of a River Delta; Renaud, F., Kuenzer, C., Eds.; Springer: New York, NY, USA, 2012; pp. 7-46.

44. Vo, Q.T.; Oppelt, N.; Leinenkugel, P.; Kuenzer, C. Remote Sensing in Mapping Mangrove Ecosystems-An Object-Based Approach. Remote Sens. 2013, 5, 183-201. [CrossRef]

45. Ottinger, M.; Vo, T.Q.; Kuenzer, C. Aquakultur im Mekong Delta. Geogr. Rundsch. 2016, 2, $24-30$.

46. GSO Statistical Data on Vietnam. Available online: http://www.gso.gov.vn (accessed on 24 July 2015).

47. Luu, T.N.M.; Garnier, J.; Billen, G.; Le, T.P.Q.; Nemery, J.; Orange, D.; Le, L.A. N, P, Si budgets for the Red River Delta (northern Vietnam): How the delta affects river nutrient delivery to the sea. Biogeochemistry 2012, 107, 241-259. [CrossRef]

48. Ngoc, L.B. Climate Change and Land Use Change of Rural Households in The Red River Delta, Vietnam. J. Econ. Dev. 2013, 15, 79-94.

49. Zhijia, L.I.U.; Heqing, H.; Werners, S.E.; Dan, Y.A.N. Construction area expansion in relation to economic-demographic development and land resource in the Pearl River Delta of China. J. Geogr. Sci. 2016, $26,188-202$.

50. Haas, J.; Ban, Y. Urban growth and environmental impacts in Jing-Jin-Ji, the Yangtze, River Delta and the Pearl River Delta. Int. J. Appl. Earth Obs. Geoinf. 2014, 30, 42-55. [CrossRef]

51. Cheng, Z.; Man, Y.B.; Nie, X.P.; Wong, M.H. Trophic relationships and health risk assessments of trace metals in the aquaculture pond ecosystem of Pearl River Delta, China. Chemosphere 2013, 90, 2142-2148. [CrossRef] [PubMed]

52. World Bank Group. East Asia's Changing Urban Landscape: Measuring a Decade of Spatial Growth; World Bank: Washington, DC, USA, 2015.

53. Kuenzer, C.; Ottinger, M.; Liu, G.; Sun, B.; Baumhauer, R.; Dech, S. Earth observation-based coastal zone monitoring of the Yellow River Delta: Dynamics in China's second largest oil producing region over four decades. Appl. Geogr. 2014, 55, 92-107. [CrossRef]

54. Ottinger, M.; Kuenzer, C.; Liu, G.; Wang, S.; Dech, S. Monitoring land cover dynamics in the Yellow River Delta from 1995 to 2010 based on Landsat 5 TM. Appl. Geogr. 2013, 44, 53-68. [CrossRef]

55. ESA. Sentinel-1 User Handbook; European Space Agency: Paris, France, 2013.

56. Torres, R.; Snoeij, P.; Geudtner, D.; Bibby, D.; Davidson, M.; Attema, E.; Potin, P.; Rommen, B.; Floury, N.; Brown, M.; et al. Remote Sensing of Environment GMES Sentinel-1 mission. Remote Sens. Environ. 2012, 120, 9-24. [CrossRef]

57. Schubert, A.; Small, D.; Miranda, N.; Geudtner, D.; Meier, E. Sentinel-1A Product Geolocation Accuracy: Commissioning Phase Results. Remote Sens. 2015, 9431-9449. [CrossRef]

58. Montero, R.S.; Bribiesca, E. State of the art of compactness and circularity measures. Int. Math. Forum 2009, 4, 1305-1335.

59. Smith, D.; John, M.; Goodchild, M.F.; Longley, P. Geospatial Analysis: A Comprehensive Guide to Principles, Techniques and Software Tools; Troubador Publishing Ltd.: Leicester, UK, 2007. 
60. Liu, C.; Shi, R. Boundary Data of Asia Tropical Humid \& Semi-Humid Eco-region (ATHSBND). Available online: http:/ /www.geodoi.ac.cn/weben/doi.aspx?Id=165 (accessed on 1 May 2017).

61. Liu, C.; Shi, R. Boundary Data of East Asia Summer Monsoon Geo_Eco_region (EASMBND). Available online: http:/ / www.geodoi.ac.cn/weben/doi.aspx?Id=201 (accessed on 1 May 2017).

62. NGA/USGS. SRTM Water Body Data Product Specific Guidance. Available online: https://dds.cr.usgs. gov/srtm/version2_1/SWBD/SWBD_Documentation/SWDB_Product_Specific_Guidance.pdf (accessed on 1 May 2017).

63. Copernicus Open Access Hub. Available online: https://scihub.copernicus.eu/ (accessed on 14 January 2016).

64. Argenti, F.; Lapini, A.; Alparone, L.; Marta, V.S. A Tutorial on Speckle Reduction in Synthetic Aperture Radar Images. IEEE Trans. Geosci. Remote Sens. Mag. 2013, 1, 6-35. [CrossRef]

65. Hellwich, O.; Mayer, H.; Winkler, G. Detection of lines in synthetic aperture radar (SAR) scenes. Proc. Int. Arch. Photogramm. Remote Sens. 1996, 31, 312-320.

66. Younos, T.M.A. Advances in Water Monitoring Research; Water Resources Publication: Highlands Ranch, CO, USA, 2002.

67. Xu, X.; Xu, S.; Jin, L.; Song, E. Characteristic analysis of Otsu threshold and its applications. Pattern Recognit. Lett. 2011, 32, 956-961. [CrossRef]

68. Otsu, N. A Threshold Selection Method from Gray-Level Histograms. IEEE Trans. Syst. Man. Cybern. 1979, 9, 62-66. [CrossRef]

69. Buades, A.; Coll, B.; Matem, D.; Km, C.V.; De Mallorca, P.; Morel, J.; Cachan, E.N.S. A Non-Local Algorithm for Image Denoising. In Proceedings of the IEEE Conference on Computer Vision and Pattern Recognition, San Diego, CA, USA, 20-26 June 2005; pp. 60-65.

70. Froment, J. Parameter-Free Fast Pixelwise Non-Local Means Denoising. Image Process. Line 2014, 4, 300-326. [CrossRef]

71. Hu, J.; Guo, R.; Zhu, X.; Baier, G.; Wang, Y. Non-Local Means Filter for Polarimetric Sar Speckle Reduction-Experiments Using Terrasar-X Data. ISPRS Ann. Photogramm. Remote Sens. Spat. Inf. Sci. 2015, II-3/W4, 71-77. [CrossRef]

72. Darbon, J.; Cunha, A.; Chan, T.F.; Osher, S.; Jensen, G.J. Fast Nonlocal Filtering Applied to Electron Cryomicroscopy. In Proceedings of the 5th IEEE International Symposium on Biomedical Imaging: From Nano to Macro, Paris, France, 14-17 May 2008; pp. 1331-1334.

73. Chambolle, A. An Algorithm for Total Variation Minimization and Applications. J. Math. Imaging Vis. 2004, 20,89-97.

74. Getreuer, P. Total variation inpainting using split bregman. Image Process. Line 2012, 2, 74-95. [CrossRef]

75. Tomasi, C. Bilateral Filtering for Gray and Color Images. In Proceedings of the 1998 IEEE International Conference on Computer Vision, Bombay, India, 7-7 January 1998.

76. Buades, A.; Bartomeu, C.; Morel, J.M. On Image Denoising Methods; Centre De Recherches Mathematiques: Montreal, QC, Canada, 2004.

77. Scikit-Image. Available online: http:/ / scikit-image.org/ (accessed on 20 January 2016).

78. Hong, S.; Jang, H.; Kim, N.; Sohn, H.G. Water area extraction using RADARSAT SAR imagery combined with landsat imagery and terrain information. Sensors 2015, 15, 6652-6667. [CrossRef] [PubMed]

79. Hahmann, T.; Roth, A.; Martinis, S.; Twele, A.; Gruber, A. Automatic extraction of water bodies from TerraSAR-X data. In Proceedings of the Boston IEEE International Geoscience and Remote Sensing Symposium (IGARSS), Boston, MA, USA, 7-11 July 2008; pp. 103-106.

80. Clewley, D.; Bunting, P.; Shepherd, J.; Gillingham, S.; Flood, N.; Dymond, J.; Lucas, R.; Armston, J.; Moghaddam, M. A python-based open source system for Geographic Object-Based Image Analysis (GEOBIA) utilizing raster attribute tables. Remote Sens. 2014, 6, 6111-6135. [CrossRef]

81. Bunting, P.; Clewley, D.; Lucas, R.M.; Gillingham, S. The Remote Sensing and GIS Software Library (RSGISLib). Comput. Geosci. 2014, 62, 216-226. [CrossRef]

82. ORFEO ToolBox Development Team. OTB CookBook Documentation. Available online: https://www.orfeotoolbox.org/packages/OTBCookBook.pdf (accessed on 1 May 2017).

83. Insight Segmentation and Registration Toolkit. Available online: https://itk.org/ (accessed on 20 January 2016).

84. Sezgin, M. Survey over image thresholding techniques and quantitative performance evaluation. J. Electr. Image 2004, 13, 146-165.

85. Li, C.H.; Lee, C.K. Minimum cross entropy thresholding. Pattern Recognit. 1993, 26, 617-625. [CrossRef] 
86. Yen, J.C.; Chang, F.J.; Chang, S. A New Criterion for Automatic Multilevel Thresholding. IEEE Trans. Image Process. 1995, 4, 370-378. [PubMed]

87. Van der Walt, S.; Schönberger, J.L.; Nunez-Iglesias, J.; Boulogne, F.; Warner, J.D.; Yager, N.; Gouillart, E.; Yu, T. Scikit-Image: Image Processing in Python. Available online: http://dx.doi.org/10.7717/peerj.453 (accessed on 1 May 2017).

88. Congalton, R.G.; Green, K. Assessing the Accuracy of Remotely Sensed Data-Principles and Practices, 2nd ed.; CRC Press: Boca Raton, FL, USA, 2009.

89. Leinenkugel, P.; Kuenzer, C.; Dech, S. Comparison and enhancement of MODIS cloud mask products for Southeast Asia. Int. J. Remote Sens. 2013, 34, 2730-2748. [CrossRef]

(C) 2017 by the authors. Licensee MDPI, Basel, Switzerland. This article is an open access article distributed under the terms and conditions of the Creative Commons Attribution (CC BY) license (http:/ / creativecommons.org/licenses/by/4.0/). 